assistance from suitable experts to create plans of action to sensitise students and doctors regarding casteism and other forms of discrimination, and to institutionalise redressal mechanisms and mental well-being avenues for those subjected to bullying and harassment. The Indian medical profession today is rightly worried about the regular incidents of abuse and violence against doctors at the hands of the public. But it is disappointing that the regular abuse and violence against doctors at the hands of other doctors (both caste-based and otherwise) has been normalised as an almost integral part of medical training. There are few organised voices, like those of the Medico Friend Circle and the Jan Swasthya Abhiyan, which consistently attempt to highlight these issues and deliberate potential solutions. It is high time the rest of the profession joined in with all their might.

\section{References}

1. Barua MP, Verma A. Workplace bullying in healthcare facilities: Role of caste and reservation. Indian J Med Ethics. 2021 Jan-Mar ;6(1) NS:44-46. DOI: 10.20529/IJME.2020.107.

2. RC Thampan and Ors vs The Principal, Medical College, Calicut, on 6 September 1978, AIR 1979 Ker 171 [cited 2020 Nov 5]. Available from: https://indiankanoon.org/doc/1851109/

3. Shantha S. Payal Tadvi suicide case: Supreme Court allows accused doctors to pursue higher education. Wire.in. 2020 Oct 8 [cited 2020 Nov 5]. Available from: https://thewire.in/law/payal-tadvi-suicide-casesupreme-court-allows-accused-doctors-to-pursue-higher-education

4. Karthikeyan D. Suicide by Dalit students in 4 years. Hindu.com. 2011 Sep 5 [cited 2020 Nov 5]. Available from: https://www.thehindu.com/ news/cities/Madurai/suicide-by-dalit-students-in-4-years/ article2425965.ece
5. Devi M. Story of Chuni Kotal. Econ Pol Wkly. 1992 Aug 29; 27(35), 18367.

6. Senthilkumar Solidarity Committee. Caste, Higher Education and Senthil's "Suicide." Econ Pol Wkly. 2008 Aug 16; 43(33): 10-12.

7. Subramanian A. The caste of merit: Engineering education in India. Harvard: Harvard University Press; 2019

8. Ruddock AL. Special medicine: Producing doctors at the All India Institute of Medical Sciences (AlIMS). PhD dissertation, University of London, King's College; 2017.

9. Lenfield SL. Michael Sandel makes the case against meritocracy. Harvard Magazine. 2020 Sep [cited 2020 Nov 6]. Available from: https:// harvardmagazine.com/2020/09/montage-michael-sandel-againstmeritocracy

10. Shantha S. Payal Tadvi case: Chargesheet reveals months of humiliation, discrimination. Wire.in. 2019 Jul 25[cited 2020 Nov 6]. Available from:https://thewire.in/rights/dr-payal-tadvi-suicidechargesheet

11. Ambedkar BR. Why BR Ambedkar's three warnings in his last speech to the Constituent Assembly resonate even today. Scroll.in. 2016 Jan 26[cited 2020 Nov 6], Available from: https://scroll.in/article/802495/ why-br-ambedkars-three-warnings-in-his-last-speech-to-theconstituent-assembly-resonate-even-today

12. Mehta PB. Why we don't talk about inequality - and how to start again. Caravan. 2012 Sep 30[cited 2020 Nov 6]. Available from: https:// caravanmagazine.in/caste/breaking-silence

13. Modak S. Payal Tadvi suicide case: MMC restores medical licences of two accused doctors, family writes to minister. Indian Express. $2020 \mathrm{Jul}$ 18[cited 2020 Nov 6]. Available from: https://indianexpress.com/ article/ india/payal-tadvi-suicide-case-mmc-revokes-medical-licencesof-two- accused-doctors-family-writes-to-minister-6511231/

14. Bhuyan, A. Even after Payal Tadvi's death, doctors' body unconvinced of caste discrimination. Wire.in. 2019 May 28[cited 2020 Nov 6] Available from: https://thewire.in/caste/payal-tadvi-doctor-castediscrimination

15. Adebowale $\mathrm{V}$, Rao M. Racism in medicine: Why equality matters to everyone. BMJ. 2020 Feb 12[cited 2020 Nov 6]; 368: m530. Available from: https://doi.org/10.1136/bmj.m530

\title{
Workplace bullying in medical institutions: Response to Karpagam
}

\author{
ANITA VERMA, MRINAL PRAKASH BARUA
}

\section{Keywords: workplace bullying, caste, suicide, discrimination}

Workplace bullying is the exhibition of repeated, hostile behaviours toward one or more individuals that are unwanted by the target(s) and cause humiliation, distress, or harm to that individual or group. (1)

In India, workplace bullying is generally actionable under the law only if bullying behaviour is directed against sections acknowledged as being vulnerable (also known as

Author: Anita Verma (anitav.psyc@aiimsrishikesh.edu.in), Senior Resident, Department of Psychiatry, All India Institute of Medical Sciences, Rishikesh, Uttarakhand INDIA; Mrinal Prakash Barua (corresponding author mrinalbarua@gmail.com), Additional Professor, Department of Anatomy, All India Institute of Medical Sciences, Rishikesh, Uttarakhand, INDIA.

To cite: Verma A, Barua MP. Workplace bullying in medical institutions: Response to Karpagam. Indian J Med Ethics. 2021 Jan-Mar; 6(1) NS: 51-52. DOI:10.20529/IJME.2021.008.

(c) Indian Journal of Medical Ethics 2020 harassment) or if it amounts to criminal wrong such as assault or battery (or sometimes "ragging"). This is bizarre considering the fact that workplace bullying is unconstitutional in the context of Articles 21, 42, 43 of the Constitution of India. We therefore assume that bullying, irrespective of the caste factor, is a serious problem. In cases of suicide, it is tricky to label bullying as abetment, even for the courts, because the perceptions of the victim are also important. The latter, unfortunately, are inaccessible hence one has to work it out retrospectively, using circumstantial evidence.

We are somewhat puzzled by Dr Karpagam's populist stance on our article. In our article (2), we had shared an observation that a culture of workplace bullying is embedded in teaching hospitals in India, and commented on how social attributes like caste could play a role. As the issue central to the article (3) is a doctor's death by suicide, perhaps as a result of bullying by her seniors, we have laid more emphasis on bullying than on its antecedents. We acknowledge that factors like caste may 
have an impact on prevalence, type and severity of bullying, but is subject to regional variations.

To have opinions about other people is an individual's personal choice, but what matters is the action that follows. The relevant issue in the context of our article is not caste. It is bullying Therefore, we feel that it is pertinent to address bullying instead of struggling to find out its causes in an attempt to fit bullying into the existing legal framework of harassment or discrimination. Instead of institutional quasijudicial grievance committees, we require comprehensive legislation in India that identifies workplace bullying as an offence In our article, we have tried to explain that the scale of the problem is greater than it seems because unless there is a caste or gender issue, bullying is not taken seriously. For most victims of workplace bullying, it still continues to linger as an occupational hazard.

Referring (4) to the "unspoken question" ("Why couldn't Dr Payal Tadvi just take harassment like everyone else does?"), we wish to reiterate that personal bias forces one to see what one wants to believe. Dr. Tadvi should not have taken the harassment. No one is expected to. It is unfortunate that people do take harassment but cannot be blamed because the alternative to tolerating bullying seems to be losing years of hard work and a promising future. Workplace bullying requires legislation.

The statement, "unprofessional behaviour is an occupational hazard rather than an offence" does not imply, as Dr Karpagam says, that "people who get into medicine have no business committing suicide because harassment is a "part of the job" take it or leave it, but don't complain about it!". Death due to occupational hazards is well known, but focussing attention on it does not mean accepting it. Acknowledging a problem is the first step towards solving it. The statement "unprofessional behaviour is an occupational hazard rather than an offence" holds true for our workplaces.

The author has also incorrectly commented, "In Dr Payal's case, she had no grievance redressal system or anti-harassment/ bullying committee or mentor to whom she could take her concerns". To mention a few, there are National Commissions for Scheduled Castes, Scheduled Tribes and Other Backward
Classes where one can register a complaint online.

We do not mean to be unempathetic towards any individual or group facing bullying or its consequences, but at the same time, we cannot let our emotions cloud our judgement and remain blind to healthcare systems that embrace and perpetuate a culture of bullying at work. Caste is a social matter. Bullying is a culture intrinsic to healthcare systems. There is no denying that the death of Dr Tadvi may have been a result of caste intersecting with bullying in a healthcare system. We agree with the author's view that the "structural enablers have to be pulled out" and the belief that it is vital to have representation from marginalised communities at all levels of the healthcare system. This is exactly why representation is a responsibility (for protecting the rights of members of one's community) or else what other purpose would representation serve? This is also why representatives must formally abstain from succumbing to "oppression". We do understand that this is a difficult proposition when the stakes are high, but history has shown us that positive social changes have happened whenever the oppressed have risen. We strongly feel that the act of bullying is intrinsically wrong, regardless of causes or consequences that may be either good or bad. In our article, we had presented our personal views and it is perfectly normal to regard some of them as no more than biases. We apologise for the fact that our dispassionate views on the matter came across as lacking in empathy.

'Do not weep. Do not wax indignant. Understand.-

Baruch Spinoza

\section{Competing interests and funding: None declared.}

\section{References}

1. Jacobson K, Hood J, Buren H. (2014). Workplace bullying across cultures: A research agenda. Int J Cross Cult Manag. 2014 Apr;14(1):4765. Doi: $10.1177 / 1470595813494192$.

2. Barua MP, Verma A. Workplace bullying in healthcare facilities. Role of caste and reservation. Indian J Med Ethics. 2021 Jan-Mar ;6(1) NS:44-46. DOI: 10.20529/IJME.2020.107.

3. Satheesh S. Payal Tadvi suicide case: The death of a doctor. Live Mint. 2019 Jun 7[cited 2020 Jul 30]. Available from: https:// www.livemint.com/mint-lounge/features/payal-tadvi-suicide-casethe-death-of-a-doctor-1559891147950.html

4. Karpagam S. Caste-washing the healthcare system will do little to address its discriminatory practices. Indian J Med Ethics. 2021 Jan-Mar; 6(1) NS:47-48. Doi:10.20529/IJME.2020.108. 